\title{
Bridging Indigenous and science-based knowledge in coastal-marine research, monitoring, and management in Canada: a systematic map protocol
}

Steven M. Alexander ${ }^{1,2^{*}}$, Jennifer F. Provencher ${ }^{3}$, Dominique A. Henri' ${ }^{4}$, Jessica J. Taylor ${ }^{5,6}$ and Steven J. Cooke ${ }^{5,6}$

\begin{abstract}
Background: The incorporation of multiple types of knowledge (e.g., science, Indigenous knowledge, traditional ecological knowledge) is an important undertaking, which can strengthen the evidence-base for policy advice, decision making, and environmental management. While the benefits of incorporating multiple types of knowledge in environmental research and management are many, successfully doing so has remained a challenge. In response there has been a number of recent reviews that have sought to better understand the what and how, when it comes to bridging Indigenous and science-based knowledge. Yet there continues to be a need for methods, models, and approaches for integrative work. This systematic map seeks to examine the extent, range, and nature of the published literature (i.e., peer-reviewed and grey) that integrates and/or includes Indigenous and science-based knowledge in coastal-marine research, monitoring, or management in Canada. Results from this study can be used to inform new and ongoing research and monitoring efforts and highlight evidence gaps.

Methods: The systematic map will aim to capture all available studies relevant to the question found in the peerreviewed and grey literature. Accordingly, the search will leverage four databases focused on peer reviewed publications, carefully selected specialist websites, and two web-based search engines. Reference sections of relevant review articles will also be cross-checked to identify articles that were not found using the search strategy. All searches will be conducted in English. Search results will be reviewed in two stages: (1) title and abstract; and (2) full text. All screening decisions will be included in the database. The systematic map will employ a narrative synthesis approach that will include the use of descriptive statistics, tables (including SM database), and figures (including map with the studies geospatially referenced). In addition, an online version of the map and queryable database will be developed similar to other knowledge mobilization tools.
\end{abstract}

Keywords: Coastal-marine management, Indigenous knowledge systems, integrative knowledge, Monitoring, Systematic map, Canada, Ecological research, Traditional ecological knowledge

\footnotetext{
*Correspondence: steven.alexander@dfo-mpo.gc.ca

${ }^{1}$ Environment and Biodiversity Sciences, Fisheries and Oceans Canada,

Ottawa, ON, Canada

Full list of author information is available at the end of the article
} 


\section{Background}

The incorporation of multiple types of knowledge (e.g., science, Indigenous knowledge, traditional ecological knowledge) is an important undertaking, which can strengthen the evidence-base for policy advice, decision making, and environmental management (e.g., [1-4]). With growing recognition of the critical role of diverse knowledge systems in environmental research and governance, there has been an increase in efforts for the integration and inclusion of local and traditional knowledge in international environmental assessments (e.g., Intergovernmental Panel on Climate Change, Millennium Ecosystem Assessment, Intergovernmental Panel on Biodiversity and Ecosystem Services) [5, 6]. Similarly, there has been a proliferation of place-based case studies which bring together different knowledge systems, shedding light on diverse species, habitats, and ecosystems globally (e.g., [7, 8]).

Knowledge systems are made up of agents, practices, routines, and institutions that organize the production, validation, transfer, and use of knowledge $[9,10]$. Here we define Indigenous knowledge systems as a "cumulative body of knowledge, practices, and beliefs, evolving and governed by adaptive processes and handed down and across (through) generations by cultural transmission, about the relationship of living beings (including humans) with one another and with their environment" [11]. Science-based knowledge systems, with roots in Greek philosophy and the Renaissance, are a fluid and evolving body of knowledge that tends to favor objectivity and reductionism [12]. There is a risk in such simplifications and the reification of knowledge systems as Indigenous and science-based knowledge systems are diverse, complex, and increasingly intertwined [13]. However, when seeking to understand and examine instances where different knowledge systems have been brought together, delineations play a role in facilitating explorations at such intersections.

The incorporation of multiple types of knowledge is referred to here as bridging knowledge systems [14$16]$. We define bridging knowledge systems as a process that maintains the integrity of each respective knowledge system while enabling the reciprocal exchange of understanding for mutual learning [15]. As [15] notes, "[t]his definition acknowledges the role of both a parallel approach to knowledge systems, as well as mutual learning and evolution/innovation of the shared knowledge base." As such, it is similar to [17] who refer to "integrative approaches" in order to capture the dynamic and co-evolving process of knowledge co-production associated with the intersection of Indigenous and science-based knowledge systems.
While the benefits of incorporating multiple types of knowledge in environmental research and management are many (e.g., [18]), successfully doing so has remained a challenge [19]. A significant body of literature has illustrated that environmental governance in Canada remains largely based on a scientific and bureaucratic framework of resource management that poses significant barriers to the meaningful inclusion of Indigenous views and knowledge [20-25]. For example, efforts to integrate Indigenous and science-based knowledge systems for the purpose of wildlife co-management in northern Canada has, in some cases, led to the decontextualization and compartmentalization of Indigenous knowledge through its translation (and distortion) into forms that can be incorporated into existing management bureaucracies and acted upon by scientists and resource managers [26-31]. Schemes for involving Indigenous peoples in environmental research and decision-making have notably been criticized for reducing Indigenous knowledge systems to a collection of mere factual data about the environment, thus failing to acknowledge the value system and cosmological context within which this knowledge was generated and within which it makes sense [32-34].

In response to the ongoing challenge of successfully bridging Indigenous and science-based knowledge there have been a number of recent reviews that have sought to better understand the what and how, when it comes to integrative approaches. For example, [15] identified four key settings for bridging knowledge systems (i.e., (i) epistemological arena; (ii) methods and processes; (iii) brokerage and networks; and (iv) institutional/governance) to enhance environmental governance while [35] evaluated processes and mechanisms for the integration of different knowledge types in the context of environmental management.

Yet there continues to be a need for methods, models, and approaches for integrative work. To this end, $[17,36]$ conducted systematic literature reviews to examine integrative methods and approaches in water research and management. Similarly, [8] identified and examined 23 published studies to better understand the methodological challenges associated with the integration of local knowledge in ecological modeling. Despite the continued growth of case studies and empirical research on the subject in coastal-marine context (see for example [37, 38]), there has been no comprehensive and systematic mapping of this growing literature. Accordingly, prior to any in-depth analysis and critical appraisal of the literature to identify best practices and approaches (e.g., [17]), it is necessary to first document the extent, range, and nature of the published literature (see "Objective of the review"). 


\section{Topic Identification and stakeholder input}

Given the Government of Canada's commitment to (i) achieving reconciliation with the Indigenous Peoples of Canada and (ii) supporting evidence-based decision making, it has become evident that there is a need to understand when, where, and how diverse knowledge systems are drawn upon in environmental research and management. Accordingly, a review of the published literature to identify methods, models, and approaches to bridge knowledge systems has been proposed by Canadian stakeholders [i.e., Fisheries and Oceans Canada (DFO)]. Due to the wide scope of such a review and the open-ended nature of the primary question (see below) we propose first undertaking a systematic map to provide an overview of literature and available case studies [39].

\section{Objective of the review}

The proposed systematic map seeks to examine the extent, range, and nature of the published literature (i.e., peer-reviewed and grey) that integrates and/or includes Indigenous and science-based knowledge in coastalmarine research, monitoring, or management in Canada.

\section{Primary question}

What methods, models, and approaches have been used in studies that seek to bridge Indigenous and sciencebased knowledge in coastal-marine research, monitoring, or management in Canada?

\section{Components of the primary question}

The primary question can be broken down into the following four components:

\section{Population}

Cases of coastal-marine research, monitoring, or management in Canada.

\section{Methods of interest}

Methods, models, and approaches used in studies that seek to bridge Indigenous and science-based knowledge.

\section{Methods}

This systematic map will follow the CEE guidelines [40] and complies with ROSES reporting standards [41] (see Additional file 1).

\section{Searching for articles}

Search strategy

The search will aim to capture all available studies relevant to the question found in the peer-reviewed and grey literature. Accordingly, the search will leverage four databases focused on peer reviewed publications, carefully selected specialist websites, and two web-based search engines (see below for more details). Finally, reference sections of relevant review articles will be cross-checked to identify articles that were not found using the search strategy.

\section{Search string}

An initial set of English search terms relevant to the different components of the research question were compiled. Next, a set of search strings was developed and modified through a scoping exercise using Web of Science Core Collections and Scopus to evaluate the sensitivity associated with alternate terms and wildcards. The terms were broken into three components and were combined using Boolean operators "AND" and/or "OR" (Table 1). The comprehensiveness of the search was tested against a collection of benchmark papers $(n=20$; Additional file 2) to ensure articles identified as relevant were being captured when possible.

All searches in the bibliographic databases will be conducted in English.

All searches of the grey literature will be conducted in English.

Table 1 Proposed search string for the execution of the search strategy using Web of Science

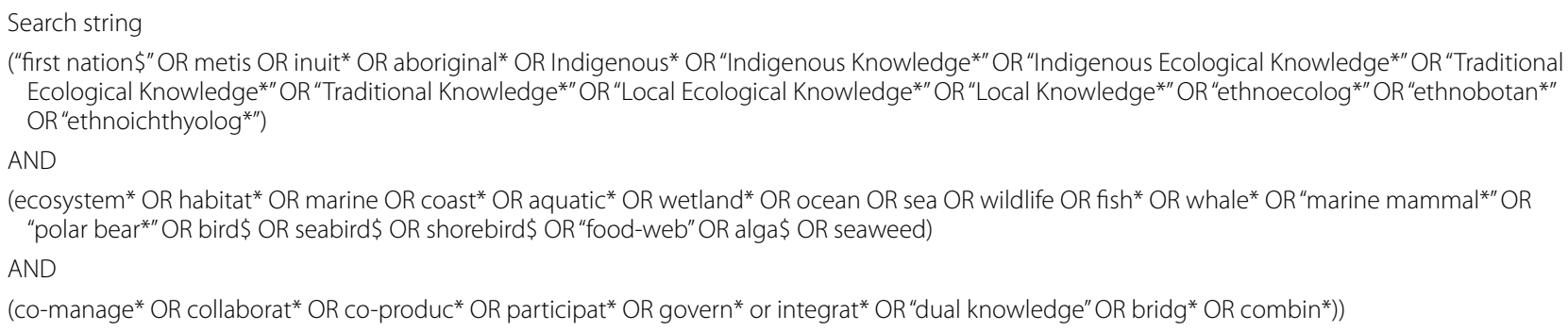

The asterisk ${ }^{*}$ ) is a wildcard and represents any characters (e.g., fish* includes fish, fishes, fishing, fisher) while the dollar sign (\$) includes zero or one character (e.g., alga\$ includes alga and algae) 


\section{Bibliographic databases}

The following online databases will be searched using subscriptions from Carleton University.

1. ISI Web of Science (Core Collection): multidisciplinary database of peer-reviewed literature, books, and conference proceedings.

2. Scopus: database of peer-reviewed literature including journals, books, and conference proceedings.

3. ProQuest Dissertations and Theses Global: database of graduate dissertations and theses from around the world.

4. Federal Science Library (Canada): database of the print collections and repositories of seven sciencebased departments and agencies (including Fisheries and Oceans Canada) providing access to departmental publications, reports, and data sets.

\section{Specialist searches for grey literature}

Due to limitations in search capabilities, the following sources can not be searched with the complete search string and will be searched using simplified search terms (e.g., Marine AND "Ecological Knowledge", Coast AND "Indigenous Knowledge"). The top 30 search results from eight simplified search strings per source, sorted by relevance, will be screened for inclusion in this systematic map.

1. Library and Archives Canada: extensive collection contains materials in all types of formats from across Canada and around the world that are of interest to Canadians including books, government records, Canadian theses, and periodicals.

2. Canadian Public Policy Collection: a collection of publications from Canadian government agencies, think-tanks, public policy institutes, advocacy groups, university research centers and other public interest groups.

3. Government of Canada Publications: a collection of over 430,000 publications.

4. Fisheries and Oceans Canada Website.

\section{Web-based search engines}

In addition to the above bibliographic databases, internet searches will be performed using Google Scholar and Google. Due to search string limitations, two different strings will be used and the first 260 hits-sorted by relevance-will be screened for their appropriateness with regards to the question guiding the systematic map.

\section{Other literature searches}

In addition to the above searches, the reference sections of relevant reviews will be hand searched for articles that are within the scope of this systematic map and not captured by the searches. We will also make use of social media and relevant email list serves to inform the community of this ongoing systematic map and request submissions of potentially relevant articles, reports, or other forms of grey literature. A targeted call for evidence will be sent to the Aboriginal Aquatic Resource and Ocean Management (AAROM) organizations $(n=33)$ and CoManagement Boards in Canada with a coastal-marine mandate $(n=10)$ as these groups often conduct or support research projects that bring together Indigenous and science-based knowledge. All submissions will be screened using the same strategy (see below) as those found in the searches and relevant submissions will be included in our final database.

\section{Estimating the comprehensiveness of the search}

The comprehensiveness of the entire search (all sources) will be tested using a collection of benchmark papers identified as relevant $(n=20$; Additional file 2). This list includes some papers that are not available in the bibliographic databases to test the effectiveness of the specialist and web-based searches.

\section{Search record database}

Search results from the online literature review will be exported into separate Zotero databases. Individual databases will then be exported into EPPI-reviewer [42] as one database. Duplicate results will be identified and merged. The final search record database, which will serve as an archive and remain untouched, will include all search results regardless of relevance.

\section{Article screening and study eligibility criteria Screening process}

Search results will be reviewed in two stages: (1) title and abstract; and (2) full text. Articles that meet the inclusion criteria at the title and abstract stage will be reviewed at the full text stage. In cases where a reviewer is uncertain about inclusion, it will be flagged for screening by a second reviewer. If there is still uncertainty, the article will be discussed by the research team until consensus has been reached regarding inclusion/exclusion. All screening decisions will be included in the database. A list of articles excluded at the full text assessment will be provided as an additional file in the systematic map with details regarding the reasons for exclusion. 


\section{Consistency checking}

Prior to the title and abstract screening, a random subset of articles ( $5 \%$ of the total) will be used for a consistency check to ensure consistent and repeatable decisions are made regarding inclusion/exclusion. The consistency check will involve a double-blind method at the title and abstract stage and be done with three reviewers to ensure the accurate interpretation of the screening criteria. Inter-rater reliability will be calculated using a Kappa test and inconsistencies will be discussed and reconciled prior to moving forward with screening. The same process will be repeated prior to screening articles at the full text stage.

\section{Eligibility criteria \\ Population}

Case studies that concern coastal-marine habitat, ecosystems, or species (incl. coastal birds, diadromous fish, and polar bears) will be included. Studies that concern exclusively freshwater or terrestrial habitat, ecosystems, or species (e.g., caribou) will be excluded.

\section{Study design}

Articles that report empirical results, either qualitatively or quantitatively, will be included. There are three broad categories of empirical studies that will be included. The first concerns studies focused on environmental/ ecological research or monitoring - those reporting on direct or indirect observation or experience from science and Indigenous knowledge. The second and third concern management and decision making. This includes empirical studies focused on the processes and practices of bridging knowledge systems in the context of decision making (e.g., narwhal co-management-[43]) and those concerned with perceptions of ecological or environmental phenomenon (e.g., perceptions of ecosystem services-[44]). Conceptual papers, perspective/opinion pieces, and review papers will be excluded. Articles where integrative knowledge or knowledge integration practices and/or methods are discussed or inferred will be included. Articles that do not include an Indigenous Knowledge component AND a scientific knowledge component will be excluded (e.g., TEK studies).

\section{Geographical scope}

Case studies conducted from across Canada's three coastal-marine regions (i.e., Atlantic, Pacific, Arctic) will be included. Case studies conducted outside of Canada will be excluded. When articles include multiple international cases where one or more are from Canada, the article is included.
A list of articles that were excluded at full text with reasons for exclusion will be provided as an Additional file with the published systematic map.

\section{Demonstrating procedural independence}

Reviewers who have authored articles to be considered within the review will be prevented from influencing inclusion decisions through the appropriate delegation of tasks.

\section{Study validity assessment}

In this systematic map we do not intend to appraise the validity of the studies.

\section{Data coding strategy}

Following the full-text screening, the remaining studies to be included will be coded using a standard questionnaire (Additional file 3). The questionnaire was designed to capture key descriptive information about the studies regarding five general categories (see next section; Additional file 3). A Google Form-which automatically compiles the results-will be developed to facilitate the coding and metadata extraction. Prior to metadata extraction, a subset of articles (5\% of included articles) will be used for a consistency check to ensure consistent and repeatable decisions are made regarding the metadata coding.

The following general categories of variables will be extracted from the articles: (1) bibliographic information; (2) study location; (3) study purpose and scope; (4) research methods and mechanisms; (5) Indigenous knowledge systems. Missing or unclear bibliographic information will be cross-referenced using the Google search engine or through contacting the authors when necessary. Missing information regarding Indigenous knowledge systems will be recorded as not reported or unspecified (see Additional file 3).

\section{Study mapping and presentation}

The systematic map will employ a narrative synthesis approach that will include the use of descriptive statistics, tables (including SM database), and figures (including a map with the studies geospatially referenced).

Framework-based synthesis will guide the development of a structured matrix which will be used to identify knowledge gaps and knowledge clusters [45, 46]. Framework-based synthesis is a matrix-based method that supports the application of both $a$ priori themes and de novo themes [45]. A structured matrix (e.g., [46]), is a powerful way to visualize the frequency and distribution of studies [47]. 
A published systematic map article will be produced and accompanied by a supporting file formatted as an MS-Excel database composed of the included studies and their associated meta-data. In addition, an online version of the map and queryable database will be developed similar to other knowledge mobilization tools such as the Evidence for Nature and People Data Portal (http:// www.natureandpeopleevidence.org). Studies will also be geospatially mapped at the appropriate resolution where discrete study boundaries are identifiable.

\section{Additional files}

Additional file 1. ROSES form for systematic map protocols.

Additional file 2. Benchmark list.

Additional file 3. Coding sheet.

\section{Authors' contributions}

The manuscript was drafted by SMA. JP, DH, JT and SJC provided comments and revisions. All authors read and approved the final manuscript.

\begin{abstract}
Author details
1 Environment and Biodiversity Sciences, Fisheries and Oceans Canada, Ottawa, ON, Canada. ${ }^{2}$ Environmental Change and Governance Group, University of Waterloo, Waterloo, ON, Canada. ${ }^{3}$ Canadian Wildlife Service, Environment and Climate Change Canada, Gatineau, QC, Canada. ${ }^{4}$ Wildlife Research Division, Science and Technology Branch, Environment and Climate Change, Gatineau, QC, Canada. ${ }^{5}$ Canadian Centre for Evidence-Based Conservation and Environmental Management, Institute of Environmental Sciences, Carleton University, Ottawa, ON, Canada. ${ }^{6}$ Fish Ecology and Conservation Physiology Laboratory, Department of Biology, Carleton University, Ottawa, ON, Canada.
\end{abstract}

\section{Acknowledgements}

The authors wish to thank the two anonymous reviewers and the editor for their constructive comments which improved the manuscript. Many thanks to David Sheppard, Reference Librarian for Fisheries and Oceans Canada, who provided early input and feedback on search strings and databases.

\section{Competing interests}

The authors declare that they have no competing interests.

\section{Availability of data and materials}

Not applicable.

\section{Consent for publication \\ Not applicable.}

Ethics approval and consent to participate

Not applicable.

\section{Funding}

The study was supported by Fisheries and Oceans Canada, and the Natural Sciences and Engineering Research Council of Canada.

\section{Publisher's Note}

Springer Nature remains neutral with regard to jurisdictional claims in published maps and institutional affiliations.

Received: 16 August 2018 Accepted: 15 March 2019

Published online: 29 March 2019

\section{References}

1. Fazey I, Fazey JA, Salisbury JG, Lindenmayer DB, Dovers S. The nature and role of experiential knowledge for environmental conservation. Environ Conserv. 2006;33(1):1.

2. Berkes F. Evolution of co-management: role of knowledge generation, bridging organizations and social learning. J Environ Manage. 2009;90:1692-702.

3. Tengö M, Brondizio ES, Elmqvist T, Malmer P, Spierenburg M. Connecting diverse knowledge systems for enhanced ecosystem governance: the multiple evidence base approach. Ambio. 2014;43(5):579-91.

4. Mistry J, Berardi A. Bridging indigenous and scientific knowledge. Science. 2016;352(6291):1274-5.

5. Sutherland WJ, Gardner TA, Haider LJ, Dicks LV. How can local and traditional knowledge be effectively incorporated into international assessments? Oryx. 2014;48(1):1-2.

6. Tengö M, Hill R, Malmer P, Raymond CM, Spierenburg M, Danielsen F, Elmqvist T, Folke C. Weaving knowledge systems in IPBES, CBD and beyond - lessons learned for sustainability. Curr Opin Environ Sustain. 2017:26:17-25

7. Gagnon CA, Berteaux D. Integrating traditional ecological knowledge and ecological science: a question of scale. Ecol Soc. 2009;14:2.

8. Bélisle AC, Asselin H, LeBlanc P, Gauthier S. Local knowledge in ecological modeling. Ecol Soc. 2018;23:2.

9. Cornell S, Berkhout F, Tuinstra W, Tàbara JD, Jäger J, Chabay I, de Wit B, Langlais R, Mills D, Moll P, Otto IM. Opening up knowledge systems for better responses to global environmental change. Environ Sci Policy. 2013;28:60-70.

10. Miller CA, Munoz-Erikson T. The rightful place of science: designing knowledge. Tempe: Consortium for Science, Policy \& Outcomes; 2018.

11. Díaz S, Demissew S, Carabias J, Joly C, Lonsdale M, Ash N, Larigauderie A, Adhikari JR, Arico S, Báldi A, Bartuska A. The IPBES conceptual framework-connecting nature and people. Cur Opin Environ Sustain. 2015;14:1-6.

12. Mazzocchi F. Western science and traditional knowledge: despite their variations, different forms of knowledge can learn from each other. EMBO Rep. 2006;7(5):463-6.

13. Agrawal A. Dismantling the divide between indigenous and scientific knowledge. Develop Change. 1995;26:413-39.

14. Reid WV, Berkes F, Wilbanks TJ, Capistrano D. Bridging scales and knowledge systems: concepts and applications in ecosystem assessment. Washington, DC: Island Press; 2006.

15. Rathwell K, Armitage D, Berkes F. Bridging knowledge systems to enhance governance of environmental commons: a typology of settings. Int J Commons. 2015;9(2):851-80.

16. Johnson JT, Howitt R, Cajete G, Berkes F, Louis RP, Kliskey A. Weaving Indigenous and sustainability sciences to diversify our methods. Sustain Sci. 2016;11(1):1.

17. Castleden HE, Hart C, Harper S, Martin D, Cunsolo A, Stefanelli R, Day L, Lauridsen K. Implementing Indigenous and Western Knowledge Systems in Water Research and Management (Part 1): a systematic realist review to inform water policy and governance in Canada. Int Indigenous Policy J. 2017;8(4):7.

18. Huntington HP. Using traditional ecological knowledge in science: methods and applications. Ecol Appl. 2000;10(5):1270-4.

19. McGregor DMD. Linking traditional ecological knowledge and western science: aboriginal perspectives from the 2000 State of the Lakes Ecosystem Conference. Can J Native Stud. 2008;28(1):139-58.

20. Stevenson MG. Indigenous knowledge in environmental assessment. Arctic. 1996:49(3):278-91.

21. Usher PJ. Traditional ecological knowledge in environmental assessment and management. Arctic. 2000;53(2):183-93.

22. Nadasdy P. Reevaluating the co-management success story. Arctic. 2003;56:367-80.

23. Menzies CR, Butler C. Introduction: understanding ecological knowledge. In: Menzies CR, editor. Traditional ecological knowledge and natural resource management. Lincoln and London: University of Nebraska Press; 2006. p. 1-20.

24. Sandlos, J. Hunters at the margins. Native people and wild life conservation in the Northwest Territories. Vancouver: University of British Columbia Press. 2007. 
25. Henri D. Managing nature, producing cultures: Inuit participation, science, and policy in wildlife governance in the Nunavut Territory, Canada. PhD thesis, University of Oxford. 2012.

26. Nadasdy P. The politics of TEK: power and the integration of knowledge. Arctic Anthropol. 1999;36:1-18.

27. Cruikshank J. The social life of stories: narrative and knowledge in the Yukon Territory. Vancouver: University of British Columbia Press; 1998.

28. Kendrick A. Community perceptions of the Beverly-Qamanirjuaq Caribou Management Board. Can J Native Stud. 2000;20(1):1-33.

29. Peters EJ. Views of traditional ecological knowledge in co-management bodies in Nunavik, Quebec. Polar Record. 2003;39(208):49-60.

30. Rodon T. En partenariat avec l'état: les expériences de co-gestion des autochtones du Canada. Québec: Les Presses de I'Université Laval; 2003.

31. Spak S. The position of indigenous knowledge in Canadian co-management organizations. Anthropologica. 2005;47(2):233-42.

32. McGregor D. The state of traditional ecological knowledge research in Canada: a critique of current theory and practice. In: Laliberte R, Settee P, Waldram J, Innes R, Macdougall B, McBain L, Barron F, editors. Expressions in Canadian Native studies. Saskatoon: University of Saskatchewan Extension Press; 2000. p. 436-58.

33. Simpson L. Aboriginal peoples and knowledge: decolonizing our processes. Can J Native Stud. 2001;21(1):137-48.

34. White G. "Not the Almighty": evaluating Aboriginal influence in northern land-claim boards. Arctic. 2008;61(1):71-85.

35. Raymond CM, Fazey I, Reed MS, Stringer LC, Robinson GM, Evely AC. Integrating local and scientific knowledge for environmental management. J Environ Manage. 2010;91(8):1766-77.

36. Stefanelli RD, Castleden H, Harper SL, Martin D, Cunsolo A, Hart C. Experiences with integrative Indigenous and Western knowledge in water research and management: a systematic realist review of literature from Canada, Australia, New Zealand, and the United States. Environ Rev. 2017;25(3):323-33.

37. Thornton TF, Scheer AM. Collaborative engagement of local and traditional knowledge and science in marine environments: a review. Ecol Soc. 2012;17(3):8.
38. Breton-Honeyman K, Furgal CM, Hammill MO. Systematic review and critique of the contributions of traditional ecological knowledge of Beluga Whales in the marine mammal literature. Arctic. 2016;69:37-46.

39. James KL, Randall NP, Haddaway NR. A methodology for systematic mapping in environmental sciences. Environ Evid. 2016;5:7.

40. Collaboration for Environmental Evidence. Guidelines and standards for evidence synthesis in environmental management. Version 5.0. In: Pullin A, Frampton G, Livoreil B, Petrokofsky G; 2018. http://www.environmen talevidence.org/information-for-authors. Accessed: 17 Aug 2018.

41. Haddaway NR, Macura B, Whaley P, Pullin AS. ROSES Reporting standards for systematic evidence syntheses: pro forma, flow-diagram and descriptive summary of the plan and conduct of environmental systematic reviews and systematic maps. Environ Evid. 2018;7:7.

42. Thomas J, Brunton J, Graziosi J. EPPI-reviewer 4: software for research synthesis. 2010.50.

43. Armitage D, Berkes F, Dale A, Kocho-Schellenberg E, Patton E. Comanagement and the co-production of knowledge: learning to adapt in Canada's Arctic. Global Environ Change. 2011;21(3):995-1004.

44. Levine J, Muthukrishna M, Chan KM, Satterfield T. Sea otters, social justice, and ecosystem-service perceptions in Clayoquot Sound, Canada. Conserv Biol. 2017;31(2):343-52

45. Dixon-Woods M. Using framework-based synthesis for conducting reviews of qualitative studies. BMC Med. 2011;9(1):39.

46. McKinnon MC, Cheng SH, Dupre S, Edmond J, Garside R, Glew L, Holland MB, Levine E, Masuda YJ, Miller DC, Oliveira I. What are the effects of nature conservation on human well-being? A systematic map of empirical evidence from developing countries. Environ Evid. 2016;5(1):8.

47. Bottrill M, Cheng S, Garside R, Wongbusarakum S, Roe D, Holland MB, Edmond J, Turner WR. What are the impacts of nature conservation interventions on human well-being: a systematic map protocol. Environ Evid. 2014;3(1):1.
Ready to submit your research? Choose BMC and benefit from:

- fast, convenient online submission

- thorough peer review by experienced researchers in your field

- rapid publication on acceptance

- support for research data, including large and complex data types

- gold Open Access which fosters wider collaboration and increased citations

- maximum visibility for your research: over 100M website views per year

At BMC, research is always in progress.

Learn more biomedcentral.com/submissions 